\title{
Updated statistics of lung and bronchus cancer in United States (2018)
}

\author{
Gabrielle Boloker, Cong Wang, Jianrong Zhang \\ George Warren Brown School, Washington University in St. Louis, St. Louis, USA \\ Correspondence to: Dr. Jianrong Zhang, MD, MPH Candidate. George Warren Brown School, Washington University in St. Louis, One Brookings \\ Drive, Campus Box 1196, St. Louis, 63130, USA. Email: Jianrong.zhang@wustl.edu. \\ Comment on: Siegel RL, Miller KD, Jemal A. Cancer statistics, 2018. CA Cancer J Clin 2018;68:7-30.
}

Submitted Jan 27, 2018. Accepted for publication Feb 27, 2018.

doi: $10.21037 /$ jtd.2018.03.15

View this article at: http://dx.doi.org/10.21037/jtd.2018.03.15

Lung and bronchus cancer is the leading cause of cancer mortality worldwide, with 1.2 million global deaths a year (1). The disease is not just a threat to human's health, but also a reflection of socioeconomic disparities, such as sex, race, and geographical area. Therefore, surveillance and estimate of its epidemiological data is crucial for disease control and social development.

According to the CA: A Cancer fournal for Clinicians, the official journal of American Cancer Society, a latest update of cancer statistics in the United States has been released (2). In 2018, a total of 234,030 estimated new lung and bronchus cancer cases will be diagnosed; both the incidence of males (121,680 cases) and females (112,350 cases) are the second highest among all cancer types. However, the trend of incidence in males has continuously declined from 1980s, in females the trend climbed from 1975 to 2005 , and slightly decreased after 2005. Different historical patterns of tobacco uptake and cessation account for the different trends between males and females: compared with males, females smoked in later time periods, and at older ages; in addition, females tended to quit smoking more slowly (2-4).

Lung and bronchus cancer continues to be the leading cause among all cancer types in both males $(83,550$ estimated deaths in 2018) and females (70,500 deaths) for more than 25 years (2). The trend of death rates in males increased by 1990 , then continuously decreased $43 \%$ until 2014; similarly, the trend in females increased until 2002, and decreased $17 \%$ to 2014 . Since sufficient evidences have been proved between smoking uptake or cessation, and the incidence and mortality of lung and bronchus cancer (5-9), the efforts on tobacco control and smoking cessation should be continued, to achieve further reduction of the incidence and mortality, especially for women.

Based on the data from 2006 to 2012, the 5-year survival rate is still low: $55 \%$ in localized stage (white: $56 \%$; black: $49 \%$ ), $28 \%$ in regional stage (white: $28 \%$; black: $25 \%$ ), $4 \%$ in distant stage (white: $4 \%$; black: $4 \%$ ), and $18 \%$ in all stages (white: 18\%; black: $15 \%$ ). As the techniques of thoracoscopic surgery, and available biomarker-driven drugs like targeted therapies and immunotherapies have been sufficiently developed for different stages of patients in recent years, the survival rate should be expected to improve in future reports.

In addition to the above annual report, the cancer statistics (to the year of 2014) in the Centers for Disease Control and Prevention (CDC) have been upgraded $(10,11)$. According to race, among the overall and male population the highest age-adjusted incidence rates (overall: 59.9 cases per 100,000 population; male: 49.5 cases per 100,000 population) and mortality rates (overall: 44.7 deaths per 100,000 population; male: 34.5 cases per 100,000 population) were in Black or African Americans; among the female population both highest rates of incidence (52.4) and mortality (36.0) were in White Americans. On the other hand, the lowest rates were in Asian or Pacific Islander regardless of sex (incidence: 32.8 overall, 26.8 in females, and 40.7 in males; mortality: 22.7 overall, 17.6 in females, and 29.7 in males). Even though the gap of incidence and mortality rates between races remained, the trend of both rates declined in a recent decade [2005-2014], especially in Black or African, White, and Indian or Alaska Native American. 


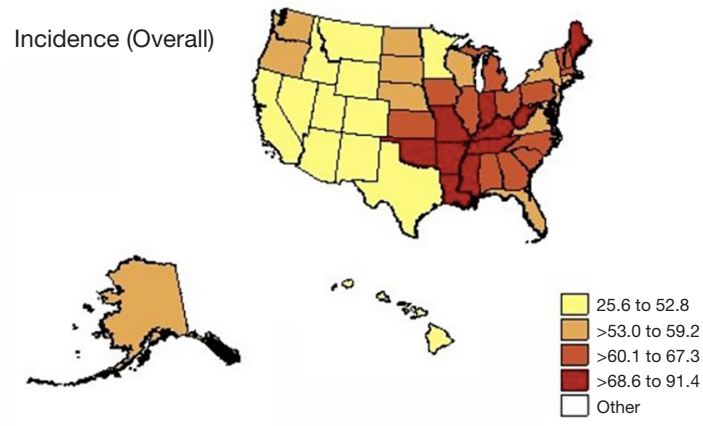

Incidence (Female)
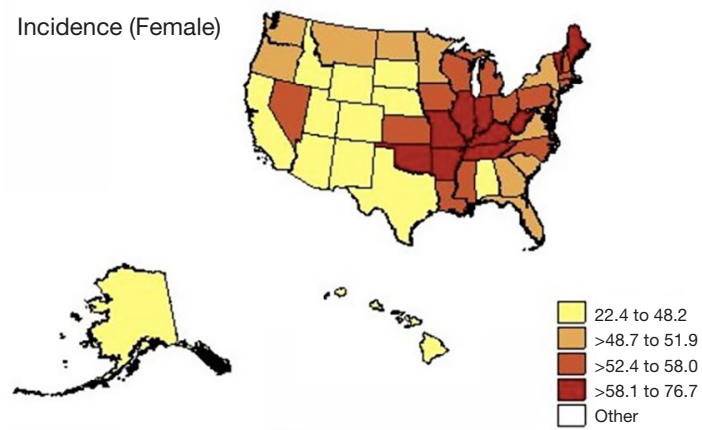

Incidence (Male)
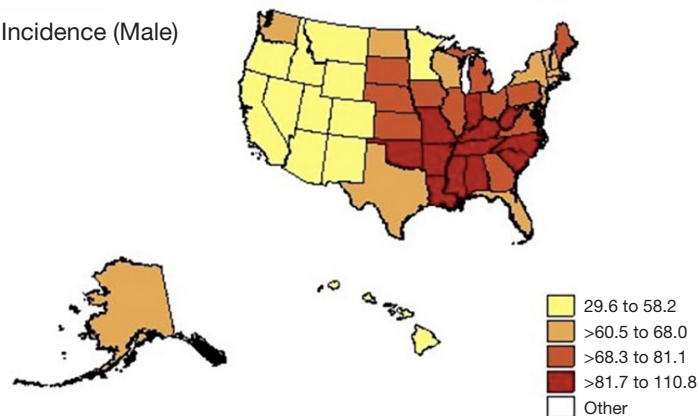
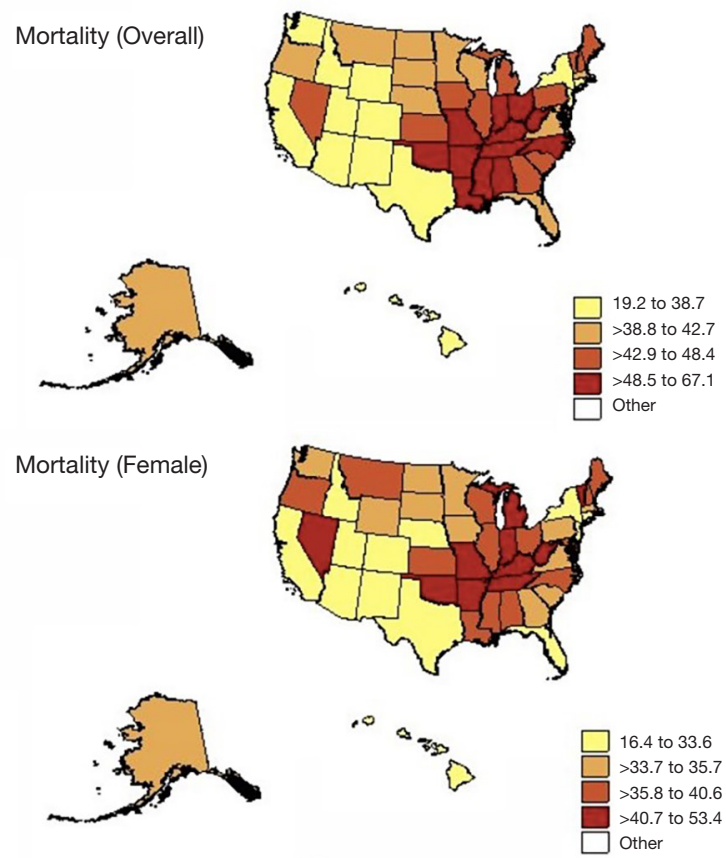

Mortality (Male)
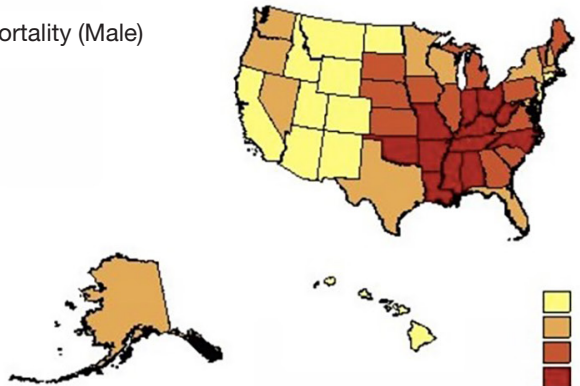

Figure 1 Map of age-adjusted incidence and mortality rates in 2014 according to states. Rates are per 100,000 and age adjusted to the 2000 US standard population.

Regardless of sex, in 2014 the state with the highest age-adjusted incidence and mortality rates was Kentucky (incidence: 91.4 overall, 76.7 in females, 110.8 in males; mortality: 67.1 overall, 53.4 in females, 85 in males); Utah was with the lowest of both incidence (overall: 26.4; female: 22.4; male: 29.6) and mortality rates (overall: 19.2; female: 16.4; male: 22.6). According to the national map, a distinct disparity existed: high incidence and mortality rates were clustered in the Central and Southeast-Central regions; nevertheless, low incidence and mortality rates were shown in the Southwest and some Western regions (Figure 1). In a recent decade from 2005 to 2014, both incidence and mortality rates presented a decline tendency in all states (especially in male population) (Figure 2). However, it is still needed for a continuous effort on narrowing the gap between states.

In conclusion, the disease burden of lung and bronchus cancer is still large, even though efforts on prevention, diagnosis and treatment have been reflected by a declined trend of the age-adjusted incidence and mortality rates. It is also important to note that, a health disparity remains between socioeconomic factors, including sex, race, and geographical area. A multidimensional intervention still need to be utilized through trans-disciplinary efforts at the individual, interpersonal, organizational, communal and public policy levels.

\section{Acknowledgements}

We sincerely thank Prof. Kimberly Johnson (George Warren Brown School, Washington University in St. Louis) 


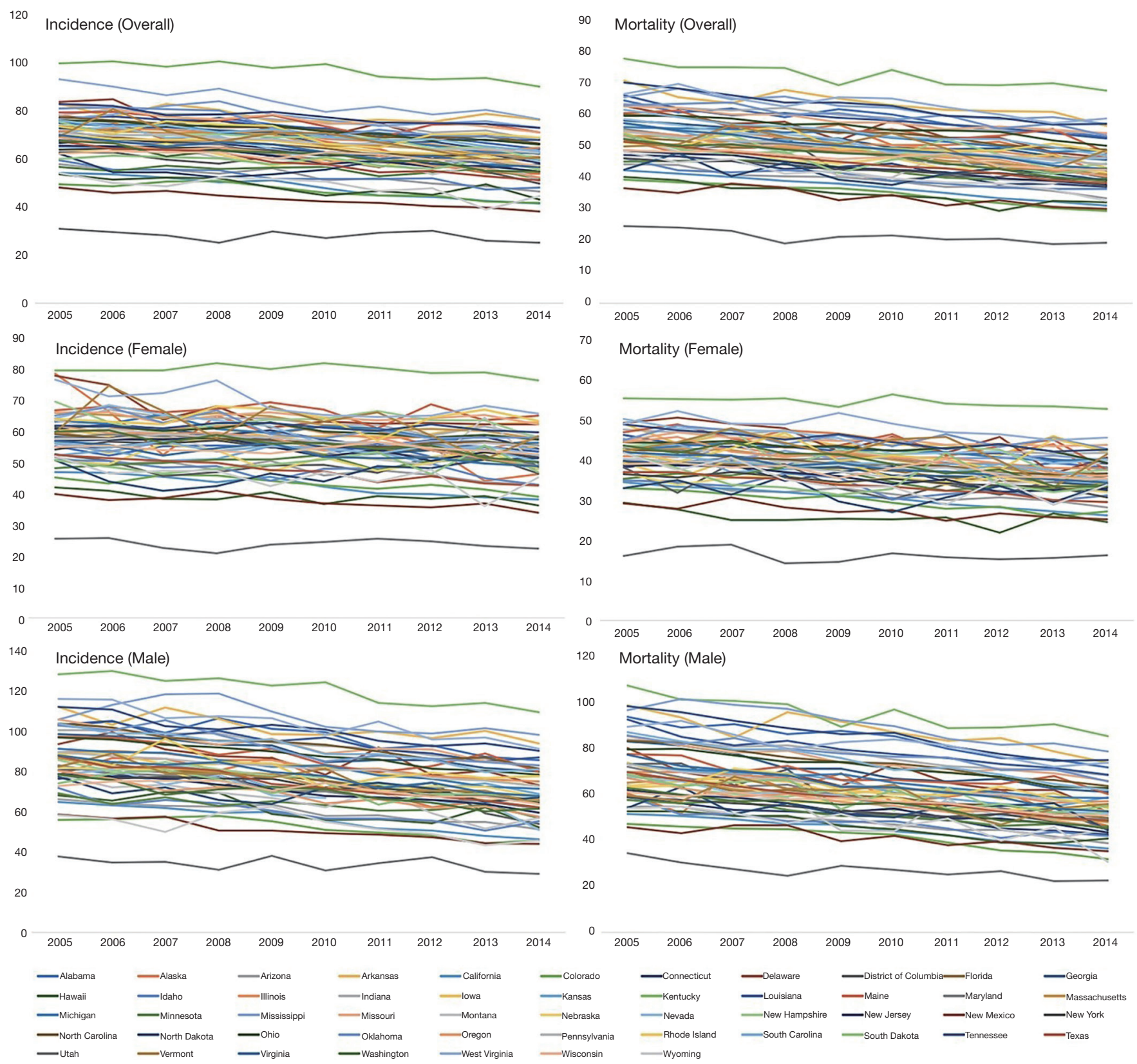

Figure 2 Trend of age-adjusted incidence and mortality rates in a recent decade [2005-2014] according to states. Rates are per 100,000 and age adjusted to the 2000 US standard population. Incident rate of Nevada in 2011 is missing.

for her efforts on teaching Epidemiology. We also thank Ms. Kalpana Bodavula (The Writing Center, Washington University in St. Louis) for providing comments on revising our paper.

\section{Footnote}

Conflicts of Interest: The authors have no conflicts of interest to declare.

\section{References}

1. Global Burden of Disease Cancer Collaboration, Fitzmaurice C, Allen C, et al. Global, regional, and national cancer incidence, mortality, years of life lost, 
years lived with disability, and disability-adjusted lifeyears for 32 cancer groups, 1990 to 2015: a systematic analysis for the global burden of disease study. JAMA Oncol 2017;3:524-48.

2. Siegel RL, Miller KD, Jemal A. Cancer statistics, 2018. CA Cancer J Clin 2018;68:7-30.

3. Harris JE. Cigarette smoking among successive birth cohorts of men and women in the United States during 1900-80. J Natl Cancer Inst 1983;71:473-9.

4. Jemal A, Ma J, Rosenberg PS, et al. Increasing lung cancer death rates among young women in southern and midwestern states. J Clin Oncol 2012;30:2739-44.

5. Jemal A, Thun MJ, Ries LA, et al. Annual report to the nation on the status of cancer, 1975-2005, featuring trends in lung cancer, tobacco use, and tobacco control. J Natl Cancer Inst 2008;100:1672-94.

6. Moolgavkar SH, Holford TR, Levy DT, et al. Impact of reduced tobacco smoking on lung cancer mortality in the United States during 1975-2000. J Natl Cancer Inst 2012;104:541-8.

Cite this article as: Boloker G, Wang C, Zhang J. Updated statistics of lung and bronchus cancer in United States (2018). J Thorac Dis 2018;10(3):1158-1161. doi: 10.21037/ jtd.2018.03.15
7. Thun MJ, Carter BD, Feskanich D, et al. 50-year trends in smoking-related mortality in the United States. N Engl J Med 2013;368:351-64.

8. Holford TR, Meza R, Warner KE, et al. Tobacco control and the reduction in smoking-related premature deaths in the United States, 1964-2012. JAMA 2014;311:164-71.

9. Gadalla SM, Widemann BC. Editorial: US Cancer Statistics of survival: achievements, challenges, and future directions. J Natl Cancer Inst 2017;109.

10. United States Cancer Statistics: 1999-2014 Incidence, WONDER Online Database. United States Department of Health and Human Services, Centers for Disease Control and Prevention and National Cancer Institute. Available online: http://wonder.cdc.gov/cancer-v2014.html

11. United States Cancer Statistics: 1999-2014 Mortality, WONDER Online Database. United States Department of Health and Human Services, Centers for Disease Control and Prevention and National Cancer Institute. Available online: http://wonder.cdc.gov/CancerMort-v2014.html 